\title{
Rendimiento de polihidroxialcanoatos (PHA) en microorganismos halófilos aislados de salinas
}

\section{Polyhydroxyalkanoates (PHA) performance of halophilic microorganisms isolated from salty lagoon}

\section{Anasilvia-Del-Pilar Flores Vásquez, Enrique-III Idrogo*, Carmen Rosa Carreño Farfán}

Facultad de Ciencias Biológicas, Universidad Nacional Pedro Ruiz Gallo. Lambayeque, Perú

*Autor de Correspondencia

Email Anasilvia Flores: anasilviadelpilar@gmail.com

Email Enrique Idrogo: enrique.idrogo@cientificagroup.com

Email Carmen Carreño: c.carrenof1@gmail.com

\section{Resumen}

En este trabajo se determinó el rendimiento de polihidroxialcanoatos (PHA) producido por microorganismos aislados de suelo y aguas de las salinas de Morrope, Lambayeque, Perú. La población de microorganismos se enriqueció con caldo HM glucosa $\left(15 \mathrm{gL}^{-1}\right)$ como fuente de carbono, modificado con 15,20 y $25 \mathrm{~g} / 100 \mathrm{~mL}$ de $\mathrm{NaCl}$, se incubó a $30{ }^{\circ} \mathrm{C}$ en aerobiosis hasta observar turbidez o película por el crecimiento se aisló en agar $\mathrm{HM}_{1}$ obteniendo cultivos de microorganismos halófilos. En caldo $\mathrm{HM}_{2}$ con glucosa $\left(30 \mathrm{gL}^{-1}\right)$, con su respectiva concentración de $\mathrm{NaCl}$ se investigó la producción de gránulos de PHA y se determinó el tiempo requerido para observar el mayor número de células con gránulos de PHA. Los 20 cultivos con mayor número de células con gránulos se llevaron a fermentación a caldo $\mathrm{HM}_{2}$, cuantificándose la biomasa y PHA. La naturaleza del polímero y cálculo del rendimiento se realizó con cinco aislados microbianos correspondientes a la mayor concentración de $\mathrm{NaCl}$, el mayor número de celular con gránulos en el menor tiempo. Se obtuvieron 234 aislados de microorganismos y en el $38.74 \%$ se observó gránulos de PHA mediante la tinción de Sudan Negro B, seleccionándose 20 cultivos de microorganismos con 40 a 85 células con gránulos de PHA. La biomasa osciló entre 0.005 a las 72 horas y $3.211 \mathrm{gL}^{-1}$ a las 240 horas. El rendimiento $\mathrm{p} / \mathrm{x}$ fue de $0.270 \mathrm{a} 0.725 \mathrm{gg}^{-1}$, destacando con más de $60 \%$ los microorganismos AE222 $(60.73 \%)$ AE2019 (63.10\%) y AE228 (72.52\%). Estos microorganismos son considerados promisorios para la producción de PHA.

Palabras clave: Archaea; bacterias; biodegradables; bioplásticos; petro-plásticos,

\section{Abstract}

In this work, we determine the polyhydroxyalkanoates (PHA) yield of microorganisms of soil and water from salty lagoons of Morrope, Lambayeque, Peru. Microorganisms were enriched in modified $\mathrm{HM}_{1}$ broth with 15,20 and $25 \mathrm{~g} / 100 \mathrm{~mL}$ of $\mathrm{NaCl}$, incubated at $30{ }^{\circ} \mathrm{C}$ in aerobiosis. After observed turbidity or film, aliquots were taken and seeded on $\mathrm{HM}_{1}$ agar obtaining 234 bacterial isolates that by lipophilic Sudan Negro B staining were observed the presence of 93 bacterial isolates with PHA granules, which were cultured in $\mathrm{HM}^{2}$ broth with their respective concentrations of $\mathrm{NaCl}$ for 144 hours, quantifying a range of 4-85 cells with granules in five microscopic fields observed, selecting 20 bacterial isolates with the presence of $40-85$ cells with granules, then they were taken to fermentation where the optimal incubation time was determined, where the cells are clearly differentiated with PHA granules. To determine the nature of the polymer produced, five bacterial isolates corresponding to the culture with the highest concentration of $\mathrm{NaCl}$ and the highest number of cells with PHA granules with the shortest growth time, but not necessarily the highest biomass, were selected, these reached $0.500 ; 0.300 ; 0.167 ; 0.183$ and 0.417 $\mathrm{gL}^{-1}$ of PHA, with $1.850 ; 0.522 ; 0.275 ; 0.290$ and $0.575 \mathrm{gL}^{-1}$ of biomass and $0.270 ; 0.575 ; 0.607 ; 0.631$ and $0.725 \mathrm{gg}^{-1}$ yield $\mathrm{Y}(\mathrm{p} / \mathrm{x})$. The highest yield was $72.52 \%$ of cellular mass in PHA being considered a promising and profitable performance for the extraction of the polymer.

Keywords: archaea; bacteria; biodegradable; bioplastics; petro-plastics.

\section{Citación:}

Flores Vásquez A.P., E.III Idrogo Baigorria, C.R. Carreño Farfán. 2018 Rendimiento de polihidroxialcanoatos (PHA) en microorganismos halófilos aislados de salinas. Revista peruana de biología 25(2): 153 - 160 (Mayo 2018). doi: http://dx.doi.org/10.15381/rpb.v25i2.14249

$$
\begin{array}{ll}
\text { Presentado: } & 31 / 01 / 2018 \\
\text { Aceptado: } & 28 / 02 / 2018
\end{array}
$$

Publicado online: 28/05/2018
Fuentes de financiamiento: Fondo de Investigación y Desarrollo para la Competitividad - FIDECOM PIPEI-7-P-044-015-13 del Ministerio de la Producción.

Información sobre los autores:

APFV y EIIIIB: muestreos de campo, análisis de laboratorio, elaboración de manuscrito; CRCF: asesoría, análisis de datos. APFV, EIIIIB y CRCF: revisaron y aprobaron el manuscrito.

Los autores no incurren en conflictos de intereses. 


\section{Introducción}

La durabilidad y resistencia a la degradación del plástico, sumado a su versátilidad, lo han convertido en una materia prima utilizada ampliamente en la producción de una gran variedad de productos; es así que su consumo se incrementó de 5 millones de toneladas al año en 1950 a cerca de 200 millones. Esto ha conllevado a una gran generación de residuos, $40 \%$ de los cuales se depositan en rellenos sanitarios y el resto contamina el ambiente terrestre y marino (Reddy et al. 2003, Salehizadeh \& Van Loosdrecht 2004).

Los bioplásticos del tipo de los polihidroxialcanoatos, PHA, biodegradables bajo condiciones aerobias y anaerobias constituyen una alternativa de solución a la problemática de los plásticos derivados del petróleo (Muhammadi et al. 2015). Los PHA son poliésteres sintetizados intracelularmente por los microorganismos como reserva de carbono y energía y que una vez extraídos de la célula, presentan propiedades físicas similares a los petroplásticos (Becerra 2013). Particularmente, el polihidroxibutirato $(\mathrm{P} 3 \mathrm{HB})$ y el polihidroxibutirato-co-hidroxivalerato $\mathrm{P}(3 \mathrm{HB} \operatorname{co} 3 \mathrm{HV})$ se producen a escala comercial, con una concentración del polímero de más de $80 \mathrm{gL}^{-1}$, una productividad de más de $2 \mathrm{gL}^{-1} \mathrm{~h}^{-1}$, en sistemas por lote alimentado o continuo, que potencialmente podrían producir 50000 toneladas por año (Salehizadeh \& Van Loosdrecht 2004).

El uso de los PHA es limitado, porque los plásticos derivados del petróleo son muy baratos, lo que hace que los procesos de producción de plásticos biodegradables no sean competitivos, cuando se analizan solo desde el punto de vista económico. En la producción de PHA se requieren grandes inversiones para los procesos de fermentación y recuperación o purificación del producto a gran escala y los sustratos para que las bacterias produzcan PHA no son suficientemente baratos (Drosg et al. 2015, Lemos \& Mina 2015). De esta manera, el costo de producción de $1 \mathrm{Kg}$ de plástico bacteriano es de 2.13 a 6.25 dólares $\mathrm{Kg}^{-1}$, comparado con 1.45 dólares $\mathrm{Kg}^{-1}$ de los plásticos derivados del petróleo (Gomez 2013).

Se han reportado más de 300 especies de microorganismos que acumulan PHA, destacando los halófilas que alcanzan más del 70\% de rendimiento (Guzman et al. 2017). La rentabilidad de un microorganismo para producir PHA a escala industrial, depende de factores como la estabilidad e inocuidad del organismo, velocidad de acumulación del polímero, velocidad de crecimiento, densidad celular que se puede alcanzar, contenido y peso molecular del polímero, facilidad de extracción, rango de fuentes de carbono utilizables, costo del medio de cultivo y generación de subproductos (Bhuwal et al. 2013, González et al. 2013, Anjum et al. 2016). En este contexto, se requiere aislar y desarrollar cepas microbianas con mayor rendimiento de PHA, que puedan utilizar sustratos baratos para disminuir los costos de producción del polímero.

Entre los microorganismos halófilos podemos encontrar especies capaces de acumular grandes cantidades del polímero, con un crecimiento rápido bajo diversas condiciones nutricionales y en sustratos de bajo costo. Los microorganismos obtenidos en la presente investigación constituyen la base para la investigación de PHA, en un proceso productivo económicamente y ambientalmente amigable, así como también para la obtención de PHA con propiedades físicas nuevas o mejoradas que permitan ampliar su uso en aplicaciones de alto valor agregado.

El presente trabajo tuvo como objetivos determinar el rendimiento de PHA de microorganismos halófilos aislados de suelo y agua de salinas ubicadas en Mórrope, Lambayeque, Perú.

\section{Materiales y métodos}

La investigación se desarrolló en dos fases. La primera correspondió al aislamiento y caracterización de los microorganismos halófilos y en la segunda se realizó la detección de gránulos de PHA y se determinó el rendimiento de PHA en los cultivos microbianos seleccionados.

Muestreo.- Para aislar microorganismos halófilos productores de PHA se recolectaron de forma aleatoria, 54 muestras de suelo y agua de las lagunas salinas ubicadas en el distrito de Mórrope, región Lambayeque, ubicadas a $21 \mathrm{~m}$ de altitud, 06 32'24”S y $80^{\circ} 00^{\prime} 46^{\prime \prime W}$. Las muestras de suelo se recolectaron (Fuentes et al. 2013) con una espátula, retirando los $5 \mathrm{~cm}$ superficiales y colectando $250 \mathrm{~g}$ que fueron depositados en frascos de vidrio previamente esterilizados. Las muestras de agua se recolectaron (Guzmán et al. 2017) sumergiendo los frascos de vidrio tapados e invertidos en las salinas hasta $10 \mathrm{~cm}$ por debajo de la superficie, luego se destaparon y se colectaron $250 \mathrm{~mL}$ de agua y se taparon herméticamente. Las muestras de suelo y agua se depositaron en una caja térmica $\left(10 \pm 1{ }^{\circ} \mathrm{C}\right)$ y se transportaron para su procesamiento al Laboratorio de Microbiología y Parasitología de la Facultad de Ciencias Biológicas de la Universidad Nacional Pedro Ruiz Gallo.

Aislamiento de microorganismos halófilos.- Las poblaciones de microorganismos halófilos de suelo y agua fueron enriquecidas (Guzmán \& Guz 2008), depositando 1 g o 1 mL en tubos de $15 \times 150 \mathrm{~mm}$ conteniendo $9 \mathrm{~mL}$ de caldo $\mathrm{HM}_{1}$ con glucosa $\left(15 \mathrm{gL}^{-1}\right)$ como fuente de carbono (Guzmán et al. 2017), modificado por los autores con 15, 20 y $25 \%$ de $\mathrm{NaCl}$. Las muestras se incubaron a $30{ }^{\circ} \mathrm{C}$, por tiempo suficiente, para observar crecimiento, denotado por turbidez o formación de película en la superficie del caldo. En cada muestra de suelo y agua con microorganismos previamente enriquecidos, se tomaron alícuotas y se sembraron por duplicado en agar $\mathrm{HM}_{1}$ con glucosa $\left(15 \mathrm{gL}^{-1}\right)$ y con una concentración de $\mathrm{NaCl}$, similar al medio de enriquecimiento (Quillaguaman et al. 2008). Después de la incubación a $30^{\circ} \mathrm{C}$, en aerobiosis hasta observar el crecimiento de colonias, éstas fueron caracterizadas macroscópicamente, registrándose la textura y el color, se cultivaron por duplicado en viales con el mismo agar de procedencia, se incubaron a 30 ${ }^{\circ} \mathrm{C}$, en aerobiosis, hasta observar crecimiento y se llevaron a refrigeración $4{ }^{\circ} \mathrm{C}$ (Guzmán et al. 2017).

Detección y cuantificación de células con gránulos de PHA.- Los microorganismos halófilos se sembraron en $5 \mathrm{~mL}$ de caldo $\mathrm{HM}_{2}$ con glucosa $\left(30 \mathrm{gL}^{-1}\right)$ como fuente de carbono (Guzmán et al. 2017) y se incubaron (estufa Blue Pard Modelo DHG) a $30{ }^{\circ} \mathrm{C}$, en agitación constante (125 rpm), por 144 horas. Posteriormente, se realizaron tinciones con Sudan Negro B (Baca et al. 2010) y la presencia de gránulos negros o grisáceos en el interior de células rosadas se consideró positiva para la detección de PHA.

Este polímero fue estimado, cuantificando el número de células microbianas con gránulos (Guzman et al. 2017), en cinco campos microscópicos y se seleccionaron los 20 cultivos microbianos que presentaron el mayor número de células con 
gránulos por campo. Éstos se cultivaron nuevamente en $5 \mathrm{~mL}$ de caldo $\mathrm{HM}_{2}$ con glucosa $\left(30 \mathrm{gL}^{-1}\right)$ a $30{ }^{\circ} \mathrm{C}$, en aerobiosis, 125 rpm y se realizaron tinciones con Sudan Negro B a las 144, 168, 192, y 216 horas, determinándose el tiempo óptimo o tiempo requerido para alcanzar el mayor número de células microbianas con gránulos (Baca et al. 2010).

Obtención de la curva patrón para la cuantificación de la biomasa.- Para cuantificar la biomasa por turbidimetría (Guzmán et al. 2017) a 600 nm $\left(\mathrm{DO}_{600}\right)$ los microorganismos halófilos reactivados en $5 \mathrm{~mL}$ de caldo $\mathrm{HM}_{2}$ con glucosa $(30 \mathrm{gL}-$ ${ }^{1}$ ) (Guzman et al. 2017) fueron cultivados en $4 \mathrm{~mL}$ del mismo caldo por el tiempo requerido para observar turbidez y luego se inocularon (5\%) en frascos de $100 \mathrm{~mL}$ de capacidad con $19 \mathrm{~mL}$ de caldo $\mathrm{HM}_{2}$, a $30{ }^{\circ} \mathrm{C}$, durante el tiempo óptimo previamente determinado. Se tomaron submuestras de $10 \mathrm{~mL}$ de cada cultivo, totalizando $200 \mathrm{~mL}$. A continuación, se tomaron por triplicado $2 \mathrm{~mL}$, uno para determinar la absorbancia a $600 \mathrm{~nm}$ (tubo 1) y otro para realizar diluciones decimales hasta $10^{-3}$ (tubos 2, 3, 4), a los que también se determinó su absorbancia. Los $194 \mathrm{~mL}$ restantes de caldo $\mathrm{HM}_{2}$ se centrifugaron a $4000 \mathrm{rpm}$, durante 20 minutos. El sedimento o biomasa se lavó rápidamente con solución salina $(0.85 \% \mathrm{NaCl})$ esterilizada, se centrifugó y deshidrató a $45^{\circ} \mathrm{C}$, hasta obtener peso constante. La biomasa deshidratada se pesó y el valor obtenido se expresó en gramos por litro $\left(\mathrm{gL}^{-1}\right)$, correspondiendo a la absorbancia de tubo 1. Asimismo, el valor de la biomasa se dividió entre 10, 100 y 1000, correspondiendo a la absorbancia de los tubos 2,3 y $4\left(10^{-1}, 10^{-2}\right.$ y $\left.10^{-3}\right)$. Con los valores obtenidos se determinó la ecuación de regresión, para calcular la biomasa de cada bacteria nativa.

Rendimiento de biomasa y PHA.- En el proceso fermentativo (Guzmán et al. 2017), cada microorganismo halófilo productor de PHA seleccionado, se cultivó en $5 \mathrm{~mL}$ de caldo $\mathrm{HM}_{2}$ con glucosa $\left(30 \mathrm{gL}^{-1}\right)$ a $30^{\circ} \mathrm{C}$, por tiempo suficiente hasta observar crecimiento denotado por turbidez. Para la obtención del inóculo bacteriano, se tomó una alícuota de cada tubo y se cultivó en $4 \mathrm{~mL}$ de caldo $\mathrm{HM}_{2}$ con glucosa $\left(30 \mathrm{gL}^{-1}\right)$ por el tiempo suficiente hasta alcanzar $10^{7}$ células $\mathrm{L}^{-1}$ (tubo 3 del nefelómetro de Mc Farland). A continuación, $1 \mathrm{~mL}$ (5\%) se inoculó por triplicado en frascos de $100 \mathrm{~mL}$ de capacidad con $19 \mathrm{~mL}$ de caldo $\mathrm{HM}_{2}$ y se incubaron a $30{ }^{\circ} \mathrm{C}$, por el tiempo óptimo requerido para alcanzar el mayor número de células bacterianas con gránulos previamente determinado.

La concentración de biomasa de cada microorganismo fue determinada por turbidimetría (Guzmán et al. 2017), cada 24 horas durante 5 días después de observar turbidez por el crecimiento bacteriano. Se tomó $1 \mathrm{~mL}$ de cada cultivo y se registró la absorbancia a $600 \mathrm{~nm}\left(\mathrm{DO}_{600}\right)$. Los valores de biomasa se calcularon en la ecuación de regresión de la curva patrón entre absorbancia y biomasa seca, previamente obtenida. Para cuantificar el PHA los $19 \mathrm{~mL}$ restantes de caldo se centrifugaron a 4000 rpm durante 20 minutos. El sedimento o biomasa celular obtenida se lavó rápidamente con solución salina $(0.85 \% \mathrm{NaCl})$ para eliminar el exceso de sales, se centrifugó y se deshidrató en estufa (Blue Pard Modelo DHG) a $45^{\circ} \mathrm{C}$, hasta alcanzar un peso constante (Baca et al. 2010), el cual se determinó con una balanza de precisión (AS 220/X Radwag). Con la biomasa, se recuperó y cuantificó el PHA producido por cada microorganismo (Cholula 2005). En el tubo que contenía la biomasa deshidratada se agregó $1 \mathrm{~mL}$ de hipoclorito de sodio al 5\%, para debilitar la membrana celular y facilitar el proceso de extracción y después de 2 horas, se adicionó $1 \mathrm{~mL}$ de cloroformo para separar la biomasa del polímero. Se observaron dos fases: una inferior transparente y una superior amarillenta. Transcurridos 20 minutos, los tubos se centrifugaron a $3500 \mathrm{rpm}$, durante 5 minutos y nuevamente se obtuvieron dos fases, una superior constituida por hipoclorito con restos celulares y una inferior conteniendo el cloroformo con el polímero, PHA. Con una pipeta Pasteur se extrajo el cloroformo con el polímero, se depositó en un tubo de 10x100 mm y se llevó a estufa a $40{ }^{\circ} \mathrm{C}$ por 24 horas. El polímero obtenido fue depositado en un papel metálico para determinar el peso (g) y verificar su naturaleza, para lo cual el polímero fue digerido con $1.5 \mathrm{~mL}$ de $\mathrm{H}_{2} \mathrm{SO}_{4}$ concentrado durante 30 minutos a $90^{\circ} \mathrm{C}$ en baño María, se dejó enfriar a temperatura ambiente $\left(25^{\circ} \mathrm{C}\right)$ y se realizó un "barrido" en el espectrofotómetro de luz ultravioleta UNICO modelo SQ-2800 (190 - $1100 \mathrm{~nm})$ en un rango de 220 a $250 \mathrm{~nm}$. El polímero fue identificado como PHA cuando se observó un pico máximo de $235 \mathrm{~nm}$ (Baca et al. 2010).

Con las concentraciones de la biomasa celular ( $\mathrm{x}$ ) y PHA (p) se calculó el $\mathrm{Y}(\mathrm{p} / \mathrm{x})$ : coeficiente de rendimiento del producto con relación a la biomasa (Dorán 1998) o cantidad de PHA obtenido por cantidad de biomasa formada $\left(\mathrm{gg}^{-1}\right)$.

$$
\left.Y\left(\frac{p}{x}\right)=\frac{\left(p-p_{i}\right)}{\left(x_{f}-x_{i}\right)}\right)=\frac{\Delta p}{\Delta x}
$$

\section{Resultados}

En las muestras de suelo y agua de las salinas de Mórrope, el contenido promedio de $\mathrm{NaCl}$ fue $27.9 \%$ y la conductividad eléctrica $558 \mathrm{dSm}^{-1}$. El 55.56\% de muestras de suelo y $62.96 \%$ de muestras de agua fueron positivas para el enriquecimiento de microorganismos, cuyo crecimiento se evidenció por turbidez (53.13\%), película blanquecina superficial $(38.38 \%)$ y coloración anaranjado - rojiza del caldo $\mathrm{HM}_{1}$ con 15, 20 y 25\% de $\mathrm{NaCl}$, en un tiempo que osciló entre 9 a 14 días para las muestras de suelo y 10 a 14 días en las muestras de agua.

El 44.44\% de muestras de suelo y 59.26\% de muestras de agua de salinas fue positivo para el aislamiento de microorganismos halófilas en 15, 20 y $25 \% \mathrm{NaCl}$, obteniéndose 234 aislados: $38.46 \%$ provenientes de muestras de suelo y $61.54 \%$ de muestras de agua. Las colonias de microorganismos halófilos observadas fueron de consistencia mucosa y pastosa, con diversos colores, predominando el anaranjado.

Los microorganismos halófilos de muestras de suelo y agua se aislaron en todas las concentraciones de $\mathrm{NaCl}$. Los microorganismos de suelo correspondieron a: $65.56 \%$ en $15 \% \mathrm{NaCl} ; 18.89 \%$ en $25 \% \mathrm{NaCl}$ y $15.56 \%$ en $20 \% \mathrm{NaCl}$. Los microorganismos de agua correspondieron a $54.86 \%$ en $15 \% \mathrm{NaCl} ; 24.31 \%$ con $25 \% \mathrm{NaCl}$ y $20.83 \%$ con $20 \% \mathrm{NaCl}$.

En el 39.74\% de los microorganismos halófilos se observaron gránulos de PHA mediante la tinción lipofílica de Sudan Negro B. El 32\% de estos microorganismos se aislaron de suelo y el $68 \%$ de agua. Los gránulos de PHA se observaron negros en el interior de las células vegetativas rosadas, que mayoritariamente fueron de forma bacilar, dispuestas aisladamente.

En muestras de suelo, los microorganismos halófilos productores de PHA correspondieron al $63.33 \%$ en $15 \% \mathrm{NaCl}$; $26.67 \%$ en $25 \% \mathrm{NaCl}$ y $10 \%$ en $20 \% \mathrm{NaCl}$. En muestras de 
agua los aislados de microorganismos halófilos productores de PHA correspondieron a $38.10 \%$ en $15 \% \mathrm{NaCl}, 31.75 \%$ en $20 \%$ $\mathrm{NaCl}$ y $30,15 \%$ en $25 \% \mathrm{NaCl}$.

En el primer cultivo de microorganismos halófilos en caldo $\mathrm{HM}_{2}$ a las 144 horas, se cuantificaron en promedio 40 a 76 células con gránulos de PHA, seleccionándose los 20 cultivos microbianos que presentaron 40 a 76 células con gránulos. En el segundo cultivo, todos los microorganismos halófilos seleccionados presentaron un tiempo óptimo de incubación, en el cual se diferenciaron claramente las células con gránulos de PHA y después del cual el número de estas células disminuyó. En el $30 \%$ de microorganismos halófilos seleccionados el número de células con PHA fue de 62 a 91 a las 144 horas, en el 35\% fue 49 a 61 a las 168 horas, en el 20\% fue 65 a 84 a las 192 horas y en el $15 \%$ fue $45-48$ a las 216 horas.

Con los valores de absorbancia obtenidos con diferentes concentraciones de biomasa de microorganismos halófilos cultivados en caldo $\mathrm{HM}_{2}$, se obtuvo $\mathrm{y}=0.069 \mathrm{x}+0.020$ como ecuación. Debido a que el valor de $\mathrm{R}^{2}$ fue mayor a 0.9 se aceptó como patrón de referencia para el cálculo de la concentración de biomasa (Mantilla 2007).

En el proceso fermentativo, la absorbancia de la biomasa de los microorganismos halófilos osciló entre 0.020 a las 72 horas con AE334 y 0.242 a las 240 horas con AE450, valores correspondientes a 0.005 y $3.211 \mathrm{gL}^{-1}$ de biomasa, respectivamente (Tabla 1). Para determinar la naturaleza del polímero producido por los microorganismos halófilos, se seleccionaron cinco cultivos de microorganismo a los que correspondió la mayor concentración de $\mathrm{NaCl}$ en el cultivo, el mayor número de células con gránulos de PHA, en el menor tiempo, pero no necesariamente la mayor biomasa (Tabla 2).

La naturaleza del polímero PHA recuperado obtenido fue verificada, obteniendo un pico máximo de absorbancia a 235 $\mathrm{nm}$. Los valores de absorbancia $(235 \mathrm{~nm})$ del PHA producido por los microorganismos halófilos oscilaron entre 0.132 y 0.323 . La concentración de PHA fue de $0.167 \mathrm{gL}^{-1}$ con el microorganismo AE222 y $0.500 \mathrm{gL}^{-1}$ con $\mathrm{AE} 339$. El rendimiento $\mathrm{Y}(\mathrm{p} / \mathrm{x})$ fue $0.270 \mathrm{gg}^{-1}$ con AE339 y $0.725 \mathrm{gg}^{-1}$ con AE228, correspondientes a 27.02 y $72.52 \%$, respectivamente (Tabla 3 ).

\section{Discusión}

La técnica del enriquecimiento de los microorganismos para el aislamiento permite aumentar la población de los organismos a investigarse (Kamagata 2015), incremento evidenciado por turbidez en medio líquido (Garzón 2015); película blanquecina superficial, típica de los microorganismos aerobios estrictos (Guzmán et al. 2017) y coloración anaranjado rojiza atribuida a los pigmentos carotenoides característicos de las haloarqueas (Castillo \& Barragan 2011).

El aislamiento de las microorganismos halófilos en medio salino fue reportado previamente por Castro et al. (2011), Fuentes et al. (2013) y Guzmán et al. (2017), quienes obtuvieron bacterias halófilas de salinas con un contenido de hasta $25 \%$ de sal. La diversa coloración y textura de las colonias microbianas encontradas fue observada también por Flores et al. (2010). Estos investigadores aislaron microorganismos halófilos que desarrollaron colonias de color naranja, crema, blanco, melón y rojo, en su mayoría de consistencia mucosa. Las haloarqueas forman colonias rosadas o rojas, debido a que sintetizan carote-

Tabla 1. Concentración $\left(\mathrm{gL}^{-1}\right)$ de biomasa de microorganismos halófilos cultivadas en glucosa como fuente de carbono

\begin{tabular}{|c|c|c|c|c|c|c|c|c|}
\hline \multirow{2}{*}{ Código bacteria } & \multicolumn{8}{|c|}{ Biomasa $\left(\mathrm{gL}^{-1}\right) /$ horas } \\
\hline & 72 & 96 & 120 & 144 & 168 & 192 & 216 & 240 \\
\hline AE339 & 0.725 & 0.816 & 0.990 & 1.850 & 1.725 & - & - & - \\
\hline AE228 & 0.000 & 0.232 & 0.473 & 0.575 & 0.565 & - & - & - \\
\hline AE343 & 0.005 & 0.256 & 0.425 & 0.522 & 0.507 & - & - & - \\
\hline AE219 & 0.000 & 0.014 & 0.087 & 0.290 & 0.261 & - & - & - \\
\hline AE222 & 0.014 & 0.048 & 0.174 & 0.275 & 0.275 & - & - & - \\
\hline AE334 & 0.000 & 0.029 & 0.072 & 0.159 & 0.145 & - & - & - \\
\hline AE212 & - & 0.164 & 0.609 & 0.459 & 2.609 & 2.609 & - & - \\
\hline AE442 & - & 1.251 & 1.444 & 1.981 & 2.517 & 2.464 & - & - \\
\hline AE444 & - & 1.280 & 1.411 & 2.014 & 2.440 & 2.391 & - & - \\
\hline AE335 & - & 0.937 & 0.855 & 0.976 & 1.280 & 1.261 & - & - \\
\hline AE338 & - & 0.077 & 0.338 & 0.681 & 0.884 & 0.855 & - & - \\
\hline AE337 & - & 0.758 & 0.686 & 0.821 & 0.797 & 0.783 & - & - \\
\hline AE353 & - & 0.372 & 0.396 & 0.077 & 0.116 & 0.101 & - & - \\
\hline AE110 & - & - & 2.628 & 3.111 & 3.749 & 4.643 & 4.609 & - \\
\hline AE065 & - & - & 1.865 & 2.295 & 3.266 & 4.222 & 4.188 & - \\
\hline AE073 & - & - & 1.971 & 2.150 & 2.386 & 3.048 & 3.014 & - \\
\hline AE415 & - & - & 0.459 & 0.903 & 1.797 & 2.092 & 2.072 & - \\
\hline AE450 & - & - & - & 2.826 & 2.913 & 3.304 & 3.415 & 3.211 \\
\hline AE432 & - & - & - & 2.580 & 2.802 & 2.870 & 3.169 & 3.947 \\
\hline AE433 & - & - & - & 1.174 & 1.227 & 1.188 & 1.382 & 1.266 \\
\hline
\end{tabular}


noides parcialmente responsables de la típica coloración rojiza de muchos ambientes naturales en los que se desarrollan en grandes cantidades (Ventosa 2006, Castillo \& Barragán 2011). En cuanto a la textura, Luque et al. (2010) concluyeron que el aspecto colonial mucoso indica posible producción de exopolisacáridos, característica confirmada en microorganismos halófilos de los géneros Halobacterium y Haloferax.

La concentración de $15 \% \mathrm{NaCl}$ facilitó el aislamiento de un mayor número de microorganismos, resultado que puede ser explicado por su requerimiento de $\mathrm{NaCl}$. Considerando el criterio de Ventosa et al. (1998) mencionado por Surve et al. (2012), en el presente estudio se aislaron microorganismos halófilos moderados $(15 \% \mathrm{NaCl})$ y extremos $(20$ y $25 \% \mathrm{NaCl})$. Al respecto, Ventosa (2006) determinó que en los ambientes hipersalinos con más de $1.5 \mathrm{M}$ (10\%) predominan los microorganismos halófilos moderados y halófilos extremos o haloarqueas.

El colorante lipofílico Sudan negro B resultó adecuado para la detección in vivo de gránulos de PHA, que se observaron grisáceos o negros en las células vegetativas rosadas, coincidiendo con Baca et al. (2010) y Legat et al. (2010). Existen otros colorantes con mayor afinidad y especificidad como el azul Nilo A y Rojo Nilo. Con éstos los gránulos de PHA son reconocidos por una fluorescencia naranja $(460 \mathrm{~nm})$ y amarillo dorado (450-500 $\mathrm{nm}$ ) o rosa-rojo $(515-560 \mathrm{~nm})$, respectivamente (Gonzales et al. 2013); sin embargo, no son completamente efectivos para la selección, porque los colorantes pueden formar cuerpos fluorescentes con los compuestos afines a los biopolímeros como son las inclusiones lipídicas (Sánchez et al. 2012).

Tabla 2. Biomasa y número de células con gránulos de PHA en microorganismos halófilos cultivadas en glucosa como fuente de carbono

\begin{tabular}{|c|c|c|c|c|c|}
\hline \multirow{2}{*}{ Código bacteria } & \multirow{2}{*}{$\mathrm{NaCl}(\%)$} & \multicolumn{2}{|c|}{ Células con gránulos PHA } & \multicolumn{2}{|c|}{ Biomasa } \\
\hline & & Número & Horas & $\left(\mathrm{gL}^{-1}\right)$ & Horas \\
\hline AE110 & \multirow{3}{*}{15} & 84 & 192 & 4.643 & 192 \\
\hline AE065 & & 81 & 192 & 4.222 & 192 \\
\hline AE073 & & 75 & 168 & 3.048 & 168 \\
\hline AE450 & \multirow{6}{*}{20} & 45 & 216 & 3.415 & 216 \\
\hline AE432 & & 48 & 216 & 3.169 & 216 \\
\hline AE442 & & 55 & 168 & 2.517 & 168 \\
\hline AE444 & & 50 & 168 & 2.440 & 168 \\
\hline AE415 & & 65 & 192 & 2.092 & 192 \\
\hline AE433 & & 47 & 216 & 1.382 & 216 \\
\hline AE212 & \multirow{11}{*}{25} & 50 & 168 & 2.609 & 168 \\
\hline AE339 & & 85 & 144 & 1.850 & 144 \\
\hline AE335 & & 49 & 168 & 1.280 & 168 \\
\hline AE338 & & 55 & 168 & 0.884 & 168 \\
\hline AE337 & & 60 & 168 & 0.821 & 168 \\
\hline AE228 & & 69 & 144 & 0.575 & 144 \\
\hline AE343 & & 81 & 144 & 0.522 & 144 \\
\hline AE219 & & 91 & 144 & 0.290 & 144 \\
\hline AE222 & & 89 & 144 & 0.275 & 144 \\
\hline AE334 & & 62 & 144 & 0.159 & 144 \\
\hline AE353 & & 61 & 168 & 0.116 & 168 \\
\hline
\end{tabular}

Tabla 3. Rendimiento $Y(p / x)$ de polihidroxialcanoatos de microorganismos halófilos

\begin{tabular}{ccccc}
\hline \multirow{2}{*}{$\begin{array}{c}\text { Código bacteria } \\
\text { UNPRG }\end{array}$} & $\begin{array}{c}\text { Biomasa } \\
\left(\mathbf{g L}^{-1}\right)\end{array}$ & $\begin{array}{c}\text { PHA } \\
\left(\mathbf{g L}^{-1}\right)\end{array}$ & \multicolumn{2}{c}{ Rendimiento $\mathbf{Y}(\mathbf{p} / \mathbf{x})$} \\
\cline { 4 - 5 } & & 0.417 & 0.725 & 72.52 \\
AE228 & 0.575 & $\left(\mathbf{g ~ g}^{-1}\right)$ & 63.10 \\
AE219 & 0.290 & 0.183 & 0.631 & 60.73 \\
AE222 & 0.275 & 0.167 & 0.607 & 57.47 \\
AE343 & 0.522 & 0.300 & 0.575 & 27.03 \\
AE339 & 1.850 & 0.500 & 0.270 & \\
\hline
\end{tabular}


El porcentaje de microorganismos en los que se observaron gránulos de PHA, superó $4.17 \%$ reportado por Guzmán et al. (2017) en bacterias y haloarqueas aisladas de salinas en caldo con 20 y $25 \% \mathrm{NaCl}$, respectivamente. Los PHA pertenecen a un grupo de poliésteres sintetizados por varios microrganismos en forma de gránulos en el citoplasma, siendo utilizados como fuente de carbono y energía en condiciones nutricionales desfavorables (López 2010, Li et al. 2016). De esta manera, bacterias productoras de PHA se han aislado en ambientes extremos como las salinas (Guzmán \& Guz 2008, Guzmán et al. 2017) suelo, agua y sedimentos de habitats con $15-18 \%$ p/v de salinidad (Luque et al. 2010), aunque también se han reportado aislados con ambientes contaminados (Razzaq et al. 2010, Sánchez et al. 2012), residuos industriales (Cardona et al. 2013) y suelo rizosférico de cultivos agrícolas (Baca et al. 2010, Lisboa \& Segura 2010).

La disminución del número de células con gránulos de PHA conforme transcurrió el tiempo es explicada por la degradación intracelular de PHA o respuesta endógena de las bacterias, que le permite hidrolizar sus reservas de carbono acumuladas en forma de PHA a monómeros hidroxialcanoatos, mediante la participación de despolimerasas intracelulares ancladas en la superficie de los gránulos (Segura et al. 2007). Estudios en P. oleovorans demostraron que antes que la bacteria complete la utilización de fuente de carbono, la célula disminuye 12 $20 \%$ la concentración de polimerasa e incrementa 10 - 15\% la despolimerasa. Este comportamiento representa la respuesta de la célula a un ambiente metabólico cada vez menos permisible, preparándose las células a movilizar las reservas de carbono para su supervivencia (Fernández 2012).

La síntesis de gránulos de $\mathrm{PHA}$ en caldo $\mathrm{HM}_{2}$ con glucosa como fuente de carbono en exceso y deficiencia de nitrógeno, coincide con Guzmán et al. (2017). Las bacterias productoras de PHA se agrupan según las condiciones para la síntesis del polímero. El primer grupo requiere la limitación de un nutriente esencial ( $\mathrm{N}, \mathrm{P}, \mathrm{S}, \mathrm{Mg}, \mathrm{O}_{2}$ ) para sintetizar PHA a partir de un exceso de carbono en la fase estacionaria de crecimiento. El segundo grupo de bacterias acumula PHA durante la fase de crecimiento, sin necesidad que se agote un nutriente esencial. Estas bacterias acumulan grandes cantidades del polímero durante la fase exponencial de crecimiento ( $>50 \%$ ), a diferencia del primer grupo, que durante esta fase acumula muy baja concentración del polímero (González et al. 2013). Investigadores como Han et al. (2007), Legat et al. (2010) y Guzmán et al. (2017) sugieren que los gránulos de PHA son sintetizados por las haloarqueas durante la fase de crecimiento. Las enzimas son constitutivas para la síntesis de PHA y el polímero se acumula continuamente a bajos niveles, independientemente de la concentración de nutrientes (Legat et al. 2010).

En la verificación de la naturaleza del PHA, el ácido crotónico producido se cuantificó por espectrofotómetría UV alcanzando un pico máximo a $235 \mathrm{~nm}$ (Apparao \& Krishnaswamy 2015). De igual manera, Baca et al. (2010) y Luque et al. (2010) verificaron la naturaleza del PHA producido por diferentes microorganismos.

La biomasa de los microorganismos halófilos se cuantificó por turbidimetría. Según Fernández (2012) en condiciones de producción de PHA, la monitorización de la turbidimetría no es un reflejo directo del número de células. El valor de la $\mathrm{DO}_{600}$ es un parámetro complejo que permite tener una idea inicial del perfil de crecimiento y producción de PHA, pero hay que tener en cuenta que se ve afectado no solo por el número de células de un cultivo sino también por la cantidad de polímero acumulado por cada célula.

Concluido el proceso fermentativo y debido a que los gránulos de PHA son intracelulares, se realizó la extracción a través de una digestión química de la membrana celular, utilizando hipoclorito de sodio. Se coincide con Salmiati et al. (2009) quienes demostraron que este agente químico en bajas concentraciones $(<10 \%)$ disuelve los componentes celulares, excepto los gránulos de PHA y permite alcanzar $86 \%$ de pureza. Para facilitar la recuperación del PHA se utilizó cloroformo como solvente orgánico, que solubiliza el polímero, siendo preferido por su rapidez y eficacia en la extracción del polímero (Naranjo 2010, Cerrone 2011). Los valores máximos en la concentración en PHA correspondieron a los aislados AE339 (0.500 $\left.\mathrm{gL}^{-1}\right)$, AE228 $\left(0.417 \mathrm{gL}^{-1}\right)$ y AE343 $\left(0.300 \mathrm{gL}^{-1}\right)$. Según Fernández et al. (2005) bacterias con más de $0.3 \mathrm{gL}^{-1}$ de PHA se consideran con potencial industrial para la producción de PHA, tomando en cuenta que el medio de cultivo empleado aún no ha sido optimizado.

El rendimiento $\mathrm{Y}(\mathrm{p} / \mathrm{x})$ no estuvo relacionado directamente con la concentración de biomasa en todos los microorganismos investigados, como sucedió con el aislado AE339 al que le correspondió el mayor valor de biomasa y el menor rendimiento, coincidiendo con Lasala et al. (2004) y Guzmán et al. (2017). Al respecto, Fernández (2012) demostró que el perfil de crecimiento de P. putida Kt 2442 es alterado por la síntesis de PHA. Investigando esta bacteria y el mutante en el gen que codifica para la polimerasa phaC1, se determinó que en condiciones de producción de PHA, las células utilizaron parte de su materia y energía para la producción de PHA, alcanzando menor masa celular en comparación con la biomasa del mutante no acumulador del polímero.

El rendimiento $\mathrm{Y}(\mathrm{p} / \mathrm{x})$ máximo alcanzado por el aislado AE228 fue $0.725 \mathrm{gg}^{-1}$, superando $0.460 \mathrm{gg}^{-1}$ y $0.348 \mathrm{gg}^{-1}$ reportados por Guzmán et al. (2017) para microorganismos halófilos aisladas de salinas. Los aislados AE228, AE219 y AE222, alcanzaron rendimientos de PHA de 60.72 - $72.52 \%$ superando el rango $21-48 \%$ mencionado por Don et al. (2006), Huang et al. (2006) y Guzmán et al. (2017). Estas bacterias son consideradas promisorias por su rendimiento, por cuanto el contenido de PHA afecta la eficiencia de extracción. Para que el proceso sea rentable es necesario que la bacteria acumule por lo menos $60 \%$ de masa celular en PHA. El rendimiento y la pureza en el proceso de extracción son dependientes del contenido de PHA y cuanto mayor es éste, menor es el costo de insumos requeridos (Dalcanton 2006). Si las condiciones de fermentación son mejoradas es posible que se incremente la acumulación de PHA. Adicionalmente estos microorganismos nativos pueden ser mejorados genéticamente para aumentar la viabilidad económica en la producción del polímero (Naranjo 2010).

\section{Conclusiones}

La producción de PHA con glucosa como fuente de carbono por los microorganismos halófilos AE 228, AE 219 y AE 222 en rendimiento $\mathrm{Y}_{(\mathrm{P} / \mathrm{X})}$ de 60.74 a $72.52 \mathrm{~g} \mathrm{~g}^{-1}$ demostró que constituyen una alternativa para la obtención de PHA en sustratos de bajo costo, y condiciones de producción mejoradas. 


\section{Agradecimientos}

Este proyecto fue financiado por el Fondo de Investigación y Desarrollo para la Competitividad - FIDECOM PIPEI7-P-044-015-13 del Ministerio de la Producción, con participación de la Universidad Nacional Pedro Ruiz Gallo y la Universidad Señor de Sipán de Lambayeque.

\section{Literatura citada}

Anjum A., M Zuber, K.M. Zia, et al. 2016. Microbial production of polyhydroxyalkanoates (PHAs) and its copolymers: A review of recent advancements. Int J Biol Macromol. 89:161-174. doi:10.1016/j.ijbiomac.2016.04.069

Apparao U., \& V.G. Krishnaswamy. 2015. Production of Polyhydroxyalkanoate (PHA) by a Moderately Halotolerant Bacterium Klebsiella pneumoniae U1 Isolated from Rubber Plantation Area. Int J Environ Bioremediat Biodegrad. 3(2):54-61. doi: 10.12691/ijebb-3-2-3

Baca K., M Sánchez, C. Carreño, et al. 2010. Polyhydroxyalcanoates of strains of Azospirillum spp. isolated of roots of Lycopersicon esculentum Mill. "tomato" and Oryza sativa L. "rice" in Lambayeque. Scientia Agropecuaria 3(1):213-224. doi:10.17268/sci.agropecu.2010.04.05

Becerra, M. 2013. Producción de un polimero tipo polihidroxialcanoato (PHA) e pleando residuos de la producción de biodiesel. Tesis, Magister en Ciencias Microbiología. Facultad de ciencias Universidad Nacional de Colombia. http://bdigital. unal.edu.co/10715/1/01186471.2013.pdf

Bhuwal A.K., G Singh, N.K. Aggarwal, et al. 2013. Isolation and Screening of Polyhydroxyalkanoates Producing Bacteria from Pulp, Paper, and Cardboard Industry Wastes. Int J Biomater. 2013:1-10. doi:10.1155/2013/752821

Cardona A., A. Mora \& M. Marín. 2013. Identificación Molecular de Bacterias Productoras de Polihidroxialcanoatos en Subproductos de Lácteos y Caña de Azúcar. Revista Facultad Nacional de Agronomía Medellin. 66(2):7129-40.

Castillo L., \& B. 2011. Barragán. Aplicaciones biotecnológicas de microorganismos halófilos. Revista Sistemas Ambientales. 4(2):45-54.

Castillo, D. 2008. Efecto Del gen fadH1en la producción de PHA conteniendo monómeros insaturados por Pseudomonas putida. Tesis, Pregrado. Facultad de Ciencias Pontificia Universidad Javeriana. http://www.javeriana.edu.co/biblos/ tesis/ciencias/tesis219.pdf

Castro L., A. Flores, A. Rodríguez, et al. 2011. Ailsamiento y caracterización de microorganismos halófilos de suelos salinos de cuatro Ciénegas Coahuila. Revista científica de la Universidad Autónoma de Coahuila. 3:5-8.

Cerrone F. 2011. Producción de poliésteres biopoliméricos (PHAs) desde alpeorujo por medio de bacterias fijadoras de nitrógeno. Tesis, Doctorado Europeo Universidad de Granada. https://hera.ugr.es/tesisugr/19655241.pdf

Cholula L. 2005. Estudio de la producción de poli- $\bigotimes$-hidroxibutirato (PHB) en Azospirillum brasilense sp7. Tesis, Maestría en Ciencias en Biotecnología Genómica Instituto Politécnico Nacional. http://tesis.ipn.mx/handle/123456789/1143

Dalcanton F. 2006. Produçao, extraçao e caracterizaçao de Poli (3hidroxibutirato) por Ralstonia eutropha em diferentes substratos. Tesis, Maestría en Ingeniería de Alimentos Universidad Federal de Santa Catarina. http://repositorio.ufsc.br/xmlui/ handle/123456789/89419

Don T.M., C.W. Chen. \& T.H. Chan. 2006. Preparation and characterization of poly (hydroxyalkanoates) from the fermentation of Haloferax mediterranei. J Biomater Sci Polym Ed. 17(12):1425-38. doi:10.1163/156856206778937208

Dorán P.M. 1998. Principios de ingeniería de los bioprocesos. Zaragoza: Acribia.

Drosg B., I. Fritz, F Gattermayr, et al. 2015. Photo-autotrophic Production of Poly(hydroxyalkanoates) in Cyanobacteria. Chem Biochem Eng Q. 29(2):145-56. doi:10.15255/ CABEQ.2014.2254
Fernández L. 2012. Estudio del metabolismo de polihidroxialcanoatos con Pseudomonas putida: implicaciones fisiológicas y aplicaciones en el desarrollo de plásticos funcionalizados. Tesis Doctoral Universidad Complutense de Madrid.

Fernández P., F. Ortiz, O. Burbano, et al. 2005. Caracterización de poli-(hidroxibutirato - co-hidroxivalerato) sintetizado por una cepa silvestre de Bacillus mycoides, FLB2. Revista Centro de Estudios en Salud. 1(6):5-12.

Flores M., A. Zavaleta, Y. Zambrano, et al. 2010. Microorganismos halófilos moderadas productoras de hidrolasas de interés biotecnológico. Ciencia e Investigación 13(1):42-6.

Fuentes A., C. Carreño, \& C. Llanos. 2013. Rendimiento de exopolisacáridos emulgentes producidos por bacterias halófilas nativas en tres concentraciones de melaza de Saccharum officinarum L. "caña de azúcar". Scientia Agropecuaria. 4: 111-120..

Garzón V.M. 2015. Aislamiento e identificación de microorganismos halófilos con potencial bioactivo aisladas de las Salinas de Zipaquirá, Colombia. Tesis, Magister en Diseño y Gestión de Procesos con énfasis en Bioprocesos Universidad de La Sabana.

González Y., J. Meza, O. Gonzáles, et al. 2013. Síntesis y biodegradación de polihidroxialcanoatos: Plásticos de origen microbiano. Rev Int Contam Ambient. 29(1):77-115.

Gomez J. 2013. Producción y Caracterización de polihidroxialcanoatos sintetizados por microorganismos nativos a partir de residuos grasos. Tesis, Maestría en Biotecnología Universidad Nacional de Colombia.

Guzmán C., A. Hurtado, C. Carreño, I. Casos. 2017. Production of polyhydroxyalkanoates by native halophilic bacteria using Solanum tuberosum L. shell starch. Sci agropecu. 8(2):109-18. doi:10.17268/sci.agropecu.2017.02.03

Guzmán M., \& H. Guz. 2008. Producción de plásticos biodegradables obtenidos de microorganismos halófilos aisladas de la laguna Blanca-Potosí Biotecnológicos. Tesis, Maestría Universidad Mayor de San Simón.

Han J., Q. Lu, L. Zhou, et al. 2007 Molecular Characterization of the phaEChm genes, required for biosynthesis of Poly(3-Hydroxybutyrate) in the extremely halophilic archaeon Haloarcula marismortui. Appl Environ Microbiol. 73(19):6058-65.

Huang T.Y., K.J. Duan, S.Y. Huang, et al. 2006. Production of polyhydroxyalkanoates from inexpensive extruded rice bran and starch by Haloferax mediterranei. J Ind Microbiol Biotechnol. 33(8):701-6. doi:10.1007/s10295-006-0098-z

Kamagata Y. 2015. Keys to cultivating uncultured microbes: Elaborate enrichment Strategies and resucitation of dormán cells. Microbes and Environments. 30(4);2089-290

Lasala F., J. Martinez, R. Nuñez, et al. 2004. Producción de polihidroxialcanoatos (PHA) por bacterias Diazótrofas II. Estudio de la sintesis a escala de Zaranda con Mesorhizobium plurifarium (4033). Revista Biológica. 18(2):136-146.

Legat A, C. Gruber, K. Zangger, et al. 2010. Identification of polyhydroxyalkanoates in Halococcus and other haloarchaeal species. Appl Microbiol Biotechnol. 87(3):1119-27. doi:10.1007/s00253-010-2611-6

Lemos A., \& A. Mina. 2015. Polihidroxialcanoatos (PHAs) producidos por bacterias y su posible aplicación a nivel industrial. Informador Técnico. 79(1):83. doi:10.23850/22565035.139

Li Z., J. Yang, \& X.J. Loh. 2016. Polyhydroxyalkanoates: opening doors for a sustainable future. NPG Asia Mater. 8(4):265. doi:10.1038/am.2016.48

Lisboa C., \& S. Segura. 2010. Rendimiento de polihidroxialcanoatos de cepas de Cupriavidus necátor aisladas de rizósfera de Zea mays "maíz", en Reque, Lambayeque, 2010. Tesis, Licenciatura Universidad Nacional Pedro Ruiz Gallo.

López A. 2010. Bioprospección de bacterias marinas productoras de polihidroxialcanoatos en tapetes microbianos contaminados. México.

Luque R., E. Quesada, V. Béjar, et al. 2010. Aislamiento de cepas del género Halomonas con interés biotecnológico en Rambla Salada (Murcia). Ars Pharm. 51:453-62.

Mantilla M. 2007. Evaluación de la acción de un bioinoculante sobre un cultivo de Cristanteno (Chrysanthemun morifolium var. Yoko ono) en período de enraizamiento. Tesis, Licenciatura Pontificia Universidad Javeriana. 
Muhammadi S., M. Afzal., \& S. Hameed. 2015. Bacterial polyhydroxyalkanoates-eco-friendly next generation plastic: Production, biocompatibility, biodegradation, physical properties and applications. Green Chem Lett Rev. 8(3-4):56-77. doi:10 $1080 / 17518253.2015 .1109715$

Naranjo J. 2010. Producción de polihidroxibutirato a partir de residuos agroindustriales. Tesis, Magister en Ingenieria Quimica Universidad Nacional de Colombia.

Quillaguamán J., T. Doan-Van, H. Guzmán, et al. 2008. Poly(3-hydroxybutyrate) production by Halomonas boliviensis in fedbatch culture. Appl Microbiol Biotechnol. 78(2):227-32. doi:10.1007/s00253-007-1297-x

Razzaq A., N. Jamil, N. Naheed, et al. 2010. Bacteria from contaminated urban and hilly areas as a source of polyhydroxyalkanoates production. Afr. J. Biotechnol. 9(13):1919-25. doi:10.5897/AJB09.1003

Reddy C., R. Ghai, Rashmi, et al. 2003. Polyhydroxyalkanoates: an overview. Bioresource Technology. 87(2):137-146.

Salehizadeh H., \& M. Van Loosdrecht. 2004. Production of polyhydroxyalkanoates by mixed culture: recent trends and biotechnological importance. Biotechnology Advances. 22(3):261-279.
Salmiati Z., R. Salim, \& G. Olsson. 2009. Recovery of polyhydroxyalkanoates (PHAs) from mixed microbial cultures by simple digestion and saponification. Malaysia: University Teknology, Institute of Environmental and Water Resource Management. 2009;8-15.

Sánchez S., M. Marín, \& A. 2012. Mora. Identificación de bacterias productoras de Polihidroxialcanoatos (PHAs) en suelos contaminados con desechos de fique. Rev. Colomb. Biotecnol. 14(2):89-100.

Segura D., R. Noguez, \& G. Espin. Contaminación ambiental y bacterias productoras de plásticos biodegradables. Una ventana al quehacer científico. Cuernavaca, Mor: UNAM, Instituto de biotecnología: Dirección general de divulgación de la Ciencia; 2007.

Surve V.V., M.U. Patil, \& S.M. Dharmadekari. 2012. Moderately halophilic bacteria from solar salt pans of ribander, goa: A comparative study. Int J Adv Biotechnol Res. 3(3):635-643.

Ventosa A. 2006. Unusual micro-organisms from unusual habitats: hypersaline environments. En: Logan NA, Lappin-Scott HM, Oyston PCF, editores. Prokaryotic diversity. Cambridge: Cambridge University Press. 223-254.

Ventosa A., J.N. Joaquín, \& A. 1998. Oren. Biology Of Moderately Halophilic Aerobic Bacteria. Microbiol Mol Rev. 62: 504544. 